whether hypertension, psychological distress, genitourinary impairment, or musculoskeletal disability, whose origins physicians must understand if they hope to treat the person, and the person as a member of a community, as well as addressing the symptoms.

Yet it is not just to be able to treat the occasional refugee that the BMA considers it important to educate its constituency in human rights issues. Ignorance of human rights permits physicians to be drawn into unacceptable practices, such as participation in the death penalty or design of inhumane weapons systems. Moreover, the world is inflicting injury on millions of people as a matter of routine oppressionand the medical profession cannot just sit by. The BMA considers it the responsibility of organised medicine to mobilise the profession towards prevention and mitigation. The goal is to propel physicians into proactive protection of individuals and populations from state inflicted harm.

This extraordinary ambition will certainly be perceived in some circles as adding an unacceptable burden to medical training and continuing education. Although the book does not take on all possible sources of resistance, it constructs reasoned limits around the notion of the "right to health," presents a nuanced argument to deflect assertions of cultural relativism, and asserts that for most medical professionals in daily practice in the West the issues raised will occur relatively infrequently. Exceptions will be among those who work with immigrant populations, in humanitarian response overseas, and in institutions, such as prisons, where the will of the state looms large.

Nevertheless, the basic thrust of this book is militantly expansive. The medical profession must move out from its narrow normative niche in medical ethics into the globalised secular debate on suffering and human values, first broached with the Geneva Conventions in 1864, continued by the Nuremberg Trials in 1945-47, and launched fully in 1948 with the Universal Declaration of Human Rights. This book marks a watershed in thinking about how to approach major violations of norms in peace and war. In this brave and laborious effort the BMA has provided the profession with a vast and vigorous perspective on the human condition that will change the life and motivation of every person who reads it.

\section{Jennifer Leaning professor of international health}

Harvard Medical School, Harvard School of Public Health, 651 Huntingdon Aveneue, Boston, MA 02115, USA (jleaning@hsph.harvard.edu)

British Medical Association. Torture report. London: BMA, 1986

British Medical Association. Medicine betrayed: the participation of doctors in human rights abuse. London: Zed Books and the BMA, 1992.

3 British Medical Association. The medical profession and human rights: a handbook for a changing agenda. London: BMA, 2001.

4 Mollica R. Mental health and the psychosocial effects of mass violence. In: Leaning J, Briggs SM, Chen LC, eds. Humanitarian crises: the medical and public health response. Cambridge, MA: Harvard University Press, 1999:125-41.

5 Summerfield D. Conflict and health: War and mental health: a brief over view. BMJ 2000;321:232-5.

6 Bedell R, Coppens K, Lefkow L, Nolan H, Shanks L, Schull MJ. Humanitarian medicine, gender and the law: Utility, inadequacy and irrelevance. J Women's Health Law 2000;1:109-24.

7 American Association for the Advancement of Science, Physicians for Human Rights. Human rights and health: the legacy of apartheid. New York: AAAS, 1998

8 Physicians for Human Rights. War crimes in Kosovo: a population-based assessment of human rights violations against Kosovar Albanians. Boston: PHR, 1999.

9 Coupland R. Towards a determination of which weapons cause "superfluous injury or unnecessary suffering." Med Global Survival 1998:5:27-34.

\title{
Electronic fetal monitoring
}

\author{
Is not necessary for low risk labours
}

$\mathrm{E}$ lectronic fetal monitoring with the cardiotocograph is standard practice during labour in most obstetric units in the United Kingdom. The technique was introduced as a screening test in the $1970 \mathrm{~s}$ in the belief that it would improve the detection of fetal hypoxaemia and reduce cerebral palsy and perinatal mortality, particularly in high risk pregnancies. Early retrospective observational studies supported the view that it was superior to intermittent auscultation using either a Pinard stethoscope or a hand held doppler ultrasound device. ${ }^{1}$ Its use spread rapidly from high risk to low risk pregnancies where the fetus is at least risk from hypoxic events in labour. Was this spread necessary or wise?

By the 1990s systematic reviews of randomised controlled trials of electronic fetal monitoring versus intermittent auscultation during labour had shown no effect on neonatal outcomes such as metabolic acidosis at birth, low Apgar scores or admissions to neonatal intensive care. ${ }^{2-4}$ An increase in neonatal seizures was seen in the group with intermittent auscultation but no long term increase in neurological problems. ${ }^{5}$

Electronic fetal monitoring did, however, have an effect on women in labour. Levels of obstetric intervention-augmentation of labour, epidural anaesthesia, instrumental delivery, and caesarean sectionconsistently increased. ${ }^{4}$ Instrumental delivery and caesarean section were even more common when electronic fetal monitoring was not backed up by fetal blood sampling. The impact on the mother and her experience of labour was therefore considerable, without any gain for the baby. In many units this evidence allowed a return to intermittent auscultation, which is less intrusive for the woman. Unfortunately the dramatic increase in litigation in obstetrics has tempered this change, as the cardiotocograph has also become an important legal document.

An admission cardiotocograph was introduced to identify fetuses at risk which needed closer monitoring during labour, allowing those with no signs of distress to be monitored by intermittent auscultation. ${ }^{6}$ In their large randomised controlled trial in this week's $B M J$ Mires et al show that even this brief cardiotocograph on admission has a similar effect in low risk women to the use of the cardiotocograph throughout labour (p 1457). ${ }^{7}$ The intervention rate increased significantly with no effect on neonatal outcome.
Papers p 1457

BMJ 2001;322:1436-7 
In low risk pregnancies adverse events during labour that affect the development of the baby are rare. Most cases of cerebral palsy have antecedents in the antenatal period, $^{8}$ with only about $10 \%$ of cases having an intrapartum cause. The prevalence of perinatal mortality or cerebral palsy from intrapartum causes is about 0.8 per 1000 and 0.1 per 1000 respectively. ${ }^{1}$ Most studies of electronic fetal monitoring were underpowered to detect these rare events and have concentrated on more immediate fetal outcomes. When perinatal mortality was studied no effect was seen. Nevertheless, the cardiotocograph continues to be an important document in many legal cases concerning cerebral palsy.

So the evidence is strongly against the routine use of electronic fetal monitoring. This is further reinforced by the publication last month of the Royal College of Obstetricians and Gynaecologists' guidelines on electronic fetal monitoring, which have been developed with the National Institute for Clinical Excellence. ${ }^{1}$ This important document has brought together all the good evidence on electronic fetal monitoring. There are some important messages, which should affect practice on labour wards throughout Britain.

The chief recommendation is that intermittent auscultation is the most appropriate method of fetal monitoring for women in labour who are low risk. This allows the best compromise between assuring fetal safety and allowing the woman mobility and independence during labour. For auscultation to be successful it needs to be frequent, especially in the second stage of labour, and therefore requires one to one care of the woman. Unfortunately this is an ideal which may be impossible in hard pressed labour wards, where midwives are often in short supply. Ironically, there is good evidence that one to one care alone has a powerful effect on the labouring woman, reducing intervention. ${ }^{8}$ The cardiotocograph can become a surrogate for this best quality care and has a major impact on the caesarean section rate.

If intermittent auscultation identifies a problem or the woman has major risk factors then electronic fetal monitoring should be used. The main problem then lies in interpreting the cardiotocograph trace. The guidelines address this at length and provide good criteria for identifying suspicious and abnormal traces. Another key recommendation is that all professionals involved in managing labour should have regular, con- tinuing training in interpreting and storing cardiotocographs. This recommendation is in line with three recent Confidential Enquiries into Stillbirths and Deaths in Infancy, which have consistently recognised inadequate interpretation of the cardiotocograph as a prime cause of adverse events. ${ }^{9-11}$ To prevent litigation trusts should act on this recommendation and ensure that such training is available free for all relevant staff.

The guidelines have also looked at other methods of testing fetal well being in early labour and of fetal monitoring, such as fetal pulse oximetry and fetal electrocardiography. These newer tools may be useful as an adjunct to electronic monitoring, but they are no more predictive of adverse outcomes. Research is needed to identify more specific tests of fetal well being that will allow us to identify babies at risk during labour without having a major impact on women. For now, it is important that electronic fetal monitoring should be used appropriately in high risk women and that intermittent auscultation is recognised as a valid form of management for most low risk cases.

Ros Goddard specialist registrar in obstetrics and gynaecology

Royal United Hospital, Bath BA1 3NG (ros_goddard@hotmail.com)

1 Royal College of Obstetricians and Gynaecologists. The use of electromic fetal monitoring: the use and interpretation of cardiotocography in intrapartum fetal surveillance. London: RCOG, 2001.

2 Neilson JP. Cardiotocography during labour. BMJ 1993;306:347-8.

3 Grant A. Monitoring the fetus during labour. In: Chalmers I, Enkin M, Keirse MJNC, eds. Effective care in pregnancy and childbirth. Oxford: Oxford University Press, 1989:846-82.

4 Thaker SB, Stroup DF, Chang M. Continuous electronic heart rate monitoring for fetal assessment during labor (Cochrane Review). Cochrane Database Syst Rev 2001;2:CD000063.

5 Grant A, O'Brien N, Joy MT, Hennessy E, MacDonald D. Cerebral palsy among children born during the Dublin randomised trial of intrapartum monitoring. Lancet 1989;8674:1233-6.

6 Ingemarsson I. Electronic fetal monitoring as a screening test. In: Spencer JAD, Ward RHT, eds. Intrapartum fetal surveillance. London: RCOG Press, 1993:45-52.

7 Mires G, Williams F, Howie P. Randomised controlled trial of cardiotocography versus Doppler auscultation of fetal heart at admission in labour in low risk obstetric population. BMJ 2001;322:1457-62.

8 Hodnett ED. Caregiver support for women during childbirth. Cochrane Database Syst Rev 2000;2:CD000199.

9 Maternal and Child Health Research Consortium. Confidential enquiry in to stillbirths and deaths in infancy: fourth annual report. London: MCHRC, 1997.

10 Maternal and Child Health Research Consortium. Confidential enquiry in to stillbirths and deaths in infancy: fifth annual report. London: MCHRC, 1998 .

11 Maternal and Child Health Research Consortium. Confidential enquiry in to stillbirths and deaths in infancy: seventh annual report. London: MCHRC, 2001.

\section{Preventing renal failure in the critically ill}

\section{There are no magic bullets-just high quality intensive care}

$\mathrm{F}$ Tew doctors trained in the past 20 years have not learnt of the benefits of "low dose" dopamine in patients developing acute renal failure. The belief that low dose dopamine is beneficial was based on the physiological and pharmacological properties of dopamine and on personal anecdotes, but there is a lack of clinical trials, those available being of poor quality. ${ }^{1}$ The recent publication of a high quality randomised, double blind, placebo controlled study ${ }^{2}$ showing no benefit of "low dose" dopamine has, there- takes time for cardiac surgeons to catch up-one of critical care's sacred cows.

In this study 328 patients (in 23 Australasian intensive care units) with an acute inflammatory response and early renal dysfunction (raised serum creatinine concentration or oliguria) randomly received a dopamine infusion $(2 \mu \mathrm{g} / \mathrm{kg} / \mathrm{min})$ or placebo. The primary outcome variable, peak serum creatinine concentration during infusion, did not differ between the well matched groups. Moreover, there was no difference in any other variable studied, including 